\title{
Molecular Cloning and Functional Characterization of a New Modulatory Cyclic Nucleotide-Gated Channel Subunit from Mouse Retina
}

\author{
Andrea Gerstner, ${ }^{1}$ Xiangang Zong, ${ }^{1}$ Franz Hofmann, ${ }^{1}$ and Martin Biel ${ }^{1,2}$ \\ 1/nstitut für Pharmakologie und Toxikologie der Technischen Universität München, 80802 München, Germany, \\ and 2Institut für Pharmazie-Zentrum für Pharmaforschung, Ludwig-Maximilians-Universität München, \\ 81377 München, Germany
}

Cyclic nucleotide-gated (CNG) channels play a key role in olfactory and visual transduction. Native CNG channels are heteromeric complexes consisting of the principal $\alpha$ subunits (CNG1-3), which can form functional channels by themselves, and the modulatory $\beta$ subunits (CNG4-5). The individual $\alpha$ and $\beta$ subunits that combine to form the CNG channels in rod photoreceptors (CNG1 + CNG4) and olfactory neurons (CNG2 + CNG4 + CNG5) have been characterized. In contrast, only an $\alpha$ subunit (CNG3) has been identified so far in cone photoreceptors. Here we report the molecular cloning of a new CNG channel subunit (CNG6) from mouse retina. The cDNA of CNG6 encodes a peptide of 694 amino acids with a predicted molecular weight of $80 \mathrm{kDa}$. Among the CNG channel subunits, CNG6 has the highest overall similarity to the CNG4 $\beta$ subunit $(47 \%$

Cyclic nucleotide-gated (CNG) channels are expressed in various cell types and tissues. Although the functional significance of CNG channel expression in most nonsensory tissues is still unclear, the role of the channels in signal transduction pathways of vertebrate sensory neurons has been well defined (Baylor, 1996; Finn et al., 1996; Schild and Restrepo, 1998). In rod and cone photoreceptors as well as in olfactory neurons, CNG channels control the influx of $\mathrm{Ca}^{2+}$ and $\mathrm{Na}^{+}$in response to signal-induced changes of cGMP or cAMP levels. CNG channels are predicted to form tetrameric structures (Gordon and Zagotta, 1995; Liu et al., 1996; Shammat and Gordon, 1999). So far, five genes encoding CNG channels have been identified in mammals (Biel et al., 1999a). These subunits have been classified as $\alpha$ and $\beta$ subunits based on expression studies. The $\alpha$ subunits (CNG1-3) can form functional CNG channels when expressed in various heterologous expression systems. The $\beta$ subunits ( $\mathrm{CNG} 4-5)$, although presumably having the same general transmembrane structure as $\alpha$ subunits, do not give rise to $\mathrm{CNG}$ channels when expressed alone. However, when combined with $\alpha$ subunits they bestow the hetero-oligomeric channels with properties that are characteristic of native photoreceptor (Chen et al., 1993; Körschen et al., 1995)

\footnotetext{
Received Sept. 9, 1999; revised Nov. 24, 1999; accepted Nov. 30, 1999.

This work was supported by grants from Deutsche Forschungsgemeinschaft, Bundesministerium für Bildung und Forschung, and Fond der Chemie. We thank K. Kohler and E. Zrenner for providing sections of mouse retina. L-cis diltiazem was kindly provided by H. Yabana (Tanabe Seiyaku Co., Japan).

GenBank Accession Number of mCNG6: AJ243572.

Correspondence should be addressed to Martin Biel, Institut für Pharmakologie und Toxikologie der Technischen Universität München, Biedersteiner Strasse 29, 80802 München, Germany. E-mail: biel@ipt.med.tu-muenchen.de.

Copyright (C) 2000 Society for Neuroscience 0270-6474/00/201324-09\$15.00/0
}

sequence identity). CNG6 transcripts are present in a small subset of retinal photoreceptor cells and also in testis. Heterologous expression of CNG6 in human embryonic kidney 293 cells did not lead to detectable currents. However, when coexpressed with the cone photoreceptor $\alpha$ subunit, CNG6 induced a flickering channel gating, weakened the outward rectification in the presence of extracellular $\mathrm{Ca}^{2+}$, increased the sensitivity for L-cis diltiazem, and enhanced the cAMP efficacy of the channel. Taken together, the data indicate that CNG6 represents a new CNG channel $\beta$ subunit that may associate with the CNG3 $\alpha$ subunit to form the native cone channel.

Key words: cone photoreceptor; cyclic nucleotide; cation channel; L-cis diltiazem; single-channel recording and olfactory (Bradley et al., 1994; Liman and Buck, 1994; Sautter et al., 1998; Bönigk et al., 1999) CNG channels. These $\beta$ subunitcontrolled channel properties include single-channel flickering, sensitivity to blockage by L-cis-diltiazem, increased apparent affinity for cyclic nucleotides, and altered interaction with $\mathrm{Ca}^{2+}$. The subunit composition of native CNG channels has been determined in two cases. First, the CNG channel of rod outer segments consists of the CNG1 $\alpha$ subunit (Kaupp et al., 1989) and the long isoform of the CNG4 $\beta$ subunit (Körschen et al., 1995). Second, the CNG channel of olfactory neurons is composed of the CNG2 $\alpha$ subunit (Dhallan et al., 1990; Ludwig et al., 1990) and two distinct $\beta$-subunits: a short isoform of CNG4 (Sautter et al., 1998; Bönigk et al., 1999) and the CNG5 subunit (Bradley et al., 1994; Liman and Buck, 1994). In contrast, the subunit composition of the cone photoreceptor CNG channel has only been partially elucidated. Expression studies (Bönigk et al., 1993; Weyand et al., 1994; Yu et al., 1996; Biel et al., 1999b), gene deletion (Biel et al., 1999b), and genetic analysis of human total color blindness (Kohl et al., 1998) indicated that the CNG3 subunit forms the $\alpha$ subunit of the native cone channel. The properties of the expressed CNG3 channel, however, are not completely consistent with the properties of native cone channels. For example, CNG3 lacks the flickery gating that is typical of native channels (Haynes and Yau, 1990; Weyand et al., 1994; Yu et al., 1996; Zong et al., 1998) and is almost insensitive to L-cis diltiazem (Biel et al., 1994). Expression studies and biochemical analysis suggest that in bovine testis CNG3 associates with a short isoform of CNG4 to form a functional channel (Biel et al., 1996; Wiesner et al., 1998). However, antibodies directed against the $\mathrm{C}$ terminus (Chen et al., 1993) or N-terminal glutamic acid- 
rich protein (GARP) domain of CNG4 (Körschen et al., 1999) did not detect the CNG4 subunit in cone photoreceptors. Likewise, the CNG5 $\beta$ subunit is not expressed in retina (Bradley et al., 1994; Liman and Buck, 1994; Bönigk et al., 1999). These data suggest that the native cone channel is composed of the CNG3 subunit and an as yet uncharacterized $\beta$ subunit.

Here we report the molecular cloning of a novel modulatory CNG channel subunit (CNG6) from mouse retina. Expression in human embryonic kidney (HEK) 293 cells indicates that CNG6 assembles with CNG3 to form a heteromeric CNG channel with properties very similar to those of the native cone photoreceptor channel.

\section{MATERIALS AND METHODS}

Cloning of $m C N G 6$. Starting out from the human expressed sequence tag (EST) HSA12972 and the sequence of rat CNG4 (Sautter et al., 1997), degenerate primers [600F: 5'-AAT/GCC/TG(TC)/GTT/TA(TC)/ TA(TC)/TGG/GC-3' and CGKRev: $5^{\prime}-\mathrm{A}(\mathrm{GA}) /(\mathrm{AG})(\mathrm{CG}) \mathrm{T} /(\mathrm{TGA}) \mathrm{AT} /$ (TC)TC/(TGCA)CC/(GA)AA-3'] were designed, and a 686 bp cDNA fragment (corresponding to $\mathrm{N}_{359}-\mathrm{L}_{587}$ of mCNG6) was amplified by RT-PCR from rat retina cDNA, cloned, and sequenced. The PCR was performed according to the following protocol: $94^{\circ} \mathrm{C}, 2 \mathrm{~min} ; 40$ cycles of $94^{\circ} \mathrm{C}, 50 \mathrm{sec} ; 51^{\circ} \mathrm{C}, 1 \mathrm{~min} ; 72^{\circ} \mathrm{C}, 2 \mathrm{~min}$; and $72^{\circ} \mathrm{C}, 5 \mathrm{~min}$. An oligo(dT)primed cDNA library was constructed in the pcDNA2 vector (Invitrogen, San Diego, CA) from $10 \mu \mathrm{g}$ of poly $\left(\mathrm{A}^{+}\right)$mRNA from mouse eye and screened with the $686 \mathrm{bp}$ fragment labeled with ${ }^{32} \mathrm{P}-\mathrm{dCTP}$. One partial clone, pcBib1, comprising nucleotide (nt) 1084-3210 of mCNG6 was obtained. The primary sequence of pcBib1 contained the $\mathrm{C}$-terminal half of the coding sequence of mCNG6 starting from the $\mathrm{S} 4$ segment and part of the $3^{\prime}$ untranslated sequence. To obtain the 5' region of the mCNG6cDNA, a specific library was constructed from mouse retina cDNA primed with CG6rev (5'-TCGATACTGCACACTCTG-3', corresponding to $\mathrm{Q}_{465}-\mathrm{R}_{470}$ of mCNG6). Screening of the library with a $329 \mathrm{bp}$ (AccI-AvaII-) fragment corresponding to $\mathrm{V}_{342}-\mathrm{M}_{451}$ of mCNG6 resulted in the isolation of one additional clone (pcBib2). The cDNA insert contained the 5' sequence of mCNG6 (nt 10-1493 of mCNG6). The sequences of pcBib1 and pcBib2 were identical over the whole overlapping sequence region. The composed cDNA sequence of pcBib1 and pcBib2 contained one open reading frame encoding a protein of 694 amino acids. Because the initiation ATG (nt 84-86) was not preceded by an in-frame stop codon, it was not clear whether the $5^{\prime}$ end of the full length cDNA was represented in pcBib2. Hence, extensive $5^{\prime}$ rapid amplification of cDNA ends (RACE) analysis was performed (Clontech Marathon kit; Clontech, Heidelberg, Germany) to determine the absolute $5^{\prime}$ end of the cDNA. Briefly, $1 \mu \mathrm{g}$ of poly $\left(\mathrm{A}^{+}\right)$mRNA from mouse retina was reverse-transcribed using primer CG6rev. The single-stranded cDNA was ligated to the Marathon adaptor and PCR-amplified using the anchor primer AP1 and the nested primers CNG276R (5'-AGAGTTTCTTCTCCATTCTCCCTT-3', nt 130-153) or CNG278R (5'-TTTGGTGATATATTTGTAGACATTG-3', nt 556-580). PCR fragments $>200 \mathrm{bp}$ were cloned into pUC18 vector. Approximately 500 colonies were hybridized with a 115 bp probe (nt 10-124) derived from the 5' end of pcBib2. The five longest clones were sequenced on both strands. They were identical with pcBib2 in the overlapping region and contained an additional $5^{\prime}$ sequence of up to $9 \mathrm{bp}$. The RACE technique was also applied to determine the complete $3^{\prime}$ end of the cDNA. Approximately $1 \mu \mathrm{g}$ of $\operatorname{poly}\left(\mathrm{A}^{+}\right)$ mRNA was reverse-transcribed using an oligo(dT) primer. The singlestranded cDNA was PCR-amplified using the specific primer CNG271F (nt 2794-2812, 5'-GTTCAAATGTCCAAAGTAG-3') and an anchor primer. The PCR profile was as follows: $94^{\circ} \mathrm{C}, 2 \mathrm{~min} ; 40$ cycles of $93^{\circ} \mathrm{C}, 30 \mathrm{sec} ; 58^{\circ} \mathrm{C}$, $1 \mathrm{~min} ; 68^{\circ} \mathrm{C}, 4 \mathrm{~min}$; and $68^{\circ} \mathrm{C}, 7 \mathrm{~min}$. PCR fragments $>700$ bp were cloned into pCR-BluntII-TOPO vector (Invitrogen). Approximately 300 colonies were hybridized with a 209 bp probe (nt 2823-3031) derived from the 3' end of pcBib1. Several positive clones were isolated and sequenced. The longest clone, $\mathrm{pc} 3^{\prime}-23$, contained an additional $1.5 \mathrm{~kb} \mathrm{3}$ ' terminus of mCNG6. In total, the cloned cDNA of CNG6 comprised $4710 \mathrm{bp}$, which is consistent with the length of the CNG6 transcript in Northern blot (4.7 kb).

Northern blot analysis. Poly $\left(\mathrm{A}^{+}\right)$mRNA $(6 \mu \mathrm{g})$ was isolated from mouse retina and size-fractioned on a $1 \%$ agarose gel, transferred to a Hybond-N membrane (Amersham Pharmacia Biotech, Freiburg, Germany), and cross-linked by ultraviolet light. Two different ${ }^{32} \mathrm{P}$-labeled probes specific for mCNG6 were used (see Fig. 2A): a 915 bp fragment (probe a, nt 1222-2136 corresponding to $\mathrm{N}_{380}-\mathrm{L}_{684}$ ) and a $1.2 \mathrm{~kb}$ fragment (probe b, nt 3169-4405) derived from pc3'-23. Probe a was also used for hybridization with a mouse multiple tissue Northern blot (Clontech). Hybridization was performed at high stringency. Radiographic exposure was for $7 \mathrm{~d}$ at $-70^{\circ} \mathrm{C}$.

In situ hybridization. ${ }^{35} \mathrm{~S}$-labeled riboprobes were synthesized in vitro in the presence of $\left({ }^{35} \mathrm{~S}\right)$-UTP using either T3 or T7 RNA polymerase (Stratagene, La Jolla, CA) for sense or antisense direction, respectively. DNA fragments representing the different probes for CNG1, CNG3, CNG4, and CNG6 were subcloned into a modified pUC19 vector (pAL1) (Ludwig et al., 1997) as follows: CNG1-probe: $183 \mathrm{bp}$, corresponding to peptide $\mathrm{I}_{458}$ to $\mathrm{V}_{517}$ of CNG1 (Barnstable and Wei, 1995); CNG4-probe: $199 \mathrm{bp}$, corresponding to $\mathrm{V}_{528}$ to $\mathrm{R}_{594}$ of CNG4.3 (Sautter et al., 1998); CNG3-probe: 263 bp [nt 1155-1417 of CNG3 (Biel et al., 1999b)]; CNG6-probe d: 253 bp (nt 1398-1650 of mCNG6). Another probe specific for CNG6 (probe c, see Fig. $1 A$ ) was obtained by cloning a PCR fragment comprising nt 125-381 of CNG6 into the pCR-BluntII-TOPO vector (Invitrogen). This was followed by transcription with T7 or SP6 RNA polymerase for sense or antisense direction, respectively. In situ hybridization was performed as described previously (Ludwig et al., 1997). Labeled slides were exposed to Kodak Bio Max film for $7 \mathrm{~d}$ and to Kodak NTB-2 film emulsion for 2 weeks (CNG1 and CNG4) or 5 weeks (CNG3 and CNG6). After development, slides were counterstained with hematoxylene/eosine and coverslipped.

Construction of the expression vector $m C N G 6-p c D N A 3$ and expression in HEK293 cells. Various strategies to clone the full length coding region of mCNG6 into the multiple cloning site of either prokaryotic or eukaryotic vectors was without success. However, in an attempt to ligate the PCR-generated HindIII-NdeI fragment (nt 84-1103) containing an optimized sequence for initiation of translation ( $5^{\prime}$-gccgccaccATG-3') and the NdeI-NheI fragment (nt 1104-2229) of mCNG6 cDNA into HindIIIXbaI-cut pcDNA3 vector (Invitrogen), a single clone was obtained (mCNG6 ${ }^{\mathrm{s}}$-pcDNA3). Sequence analysis of mCNG6 ${ }^{\mathrm{s}}$-pcDNA3 revealed that this clone was identical to the cDNA sequence of mCNG6 with the exception of a single point mutation at position nt 1112 leading to a stop codon (TAC $\rightarrow$ TAA). This finding led to the assumption that Escherichia coli produced a toxic gene product from mCNG6, possibly by using an internal promoter for mRNA transcription and by initiating protein translation at a starting point localized upstream of nt 1112. By PCR analysis the region responsible for the toxicity of wild-type mCNG6 could be further narrowed down to the region between nt 1020 and 1112 . To prevent transcription and protein translation in E. coli, the sequence of mCNG6 had to be modified as follows. (1) The methionine upstream of the spontaneous stop mutation $\left(\mathrm{M}_{337}\right.$ corresponding to nt 1092-1094) was mutated to a leucine, which is the amino acid that rCNG4 carries at equivalent position (see Fig. $1 A$ ). The position corresponding to $\mathrm{M}_{337}$ is not conserved in the CNG channel family, making it very unlikely that channel properties are affected by the exchange. (2) To suppress a possible internal promotor function, six silent mutations (T1064C, C1079T, G1082T, T1088G, A1091C, T1106C) were introduced in the vicinity of the putative start codon that did not change the amino acid sequence encoded by mCNG6. The introduction of the silent mutations without the replacement of $\mathrm{M}_{337}$ by leucine was not sufficient to prevent toxicity in E. coli. The integrity of the modified mCNG6 cDNA was verified by sequencing. The eukaryotic expression vector mCNG6pcDNA3 was obtained by inserting the modified mCNG6 sequence (nt 84-2229), including an optimized Kozak sequence, into the HindIII$X b a I$ site of the pcDNA3 plasmid. The DNA of mCNG6-pcDNA3 was well propagated in E. coli and used for transient expression in HEK293 cells after calcium phosphate transfection. mCNG6-pcDNA3 was used either alone or in combination with equimolar amounts of plasmid pcGK26/CMV (Biel et al., 1994) encoding the bovine CNG3 channel. To demonstrate the correctness of the cloning procedures and to control expression in cell culture, the modified cDNA of mCNG6 was also cloned into pcDNA3.1/Myc-His vector (Invitrogen). As predicted from the primary sequence, a monoclonal antibody directed against the C-terminal myc epitope recognized a specific band of $\sim 80 \mathrm{kDa}$ in membrane fractions of HEK293 cells transfected with the expression vector (data not shown).

Electrophysiological experiments. Macroscopic currents and singlechannel currents were recorded from inside-out patches excised from HEK293 cells by using an Axopatch 200B amplifier and pCLAMP7 software (Axon Instruments, Foster City, CA). The pipette and bath solution were identical and contained (in $\mathrm{mm}$ ): $140 \mathrm{NaCl}, 5.0 \mathrm{KCl}, 10$ 
HEPES, 1.0 EGTA (divalent cation-free solution, pH 7.4 with $\mathrm{NaOH}$ ). For measurement of the currents in the presence of extracellular $\mathrm{Ca}^{2+}$, the following solution was used in the pipette (in $\mathrm{mM}$ ): $140 \mathrm{NaCl}, 5.0$ $\mathrm{KCl}, 2 \mathrm{CaCl}_{2}, 10 \mathrm{HEPES}, \mathrm{pH}$ 7.4. A multi-barreled perfusion pipette placed $200 \mu \mathrm{m}$ away from the patch was used to switch the superfusion solution. The membrane potential was held at $0 \mathrm{mV}$ and stepped for 200 msec to $\pm 100 \mathrm{mV}$. The macroscopic current was defined as the mean current measured during a $200 \mathrm{msec}$ voltage step. Capacitative transients and leak currents were subtracted using currents recorded under the superfusion with solution without agonist. Data were filtered at $2 \mathrm{kHz}$, digitized at $20 \mathrm{kHz}$, and analyzed with Clampfit and Fetchan software (Axon Instruments). Dose-response curves for cGMP and cAMP were generated by measuring the current response at $+60 \mathrm{mV}$ and fitted with the Hill equation: $I / I_{\max }=(C)^{\nu} /\left((C)^{\nu}+K_{\mathrm{a}}{ }^{\nu}\right)$, where $I_{\max }$ is the current at a saturating concentration $(1 \mathrm{mM})$ of cGMP,$(C)$ is the cyclic nucleotide concentration, $\mathrm{K}_{\mathrm{a}}$ is the activation constant, and $\nu$ is the Hill coefficient.

Spontaneous channel activity was determined by applying $200 \mathrm{msec}$ depolarization pulses from 0 to $+80 \mathrm{mV}$ at a frequency of $0.5 \mathrm{~Hz}$. The mean spontaneous current $\left(I_{\mathrm{sp}}\right)$ was determined by averaging the current from 50 pulses. For baseline correction, five blank traces containing no opening event were averaged and subtracted from each current trace. At the end of each recording of spontaneous activity, $300 \mu \mathrm{M}$ of cGMP was applied to the same patch to determine the maximal current amplitude $\left(I_{\max }\right)$. The number of channels present in the patch $(n)$ was calculated using $n=I_{\max } / i$, where $i$ is the single-channel current. It was assumed that the open probability of the channels at saturating cGMP concentrations $\left(P_{\max , ~ c G M P}\right)$ equals 1 . Although the $P_{\max }$ cGmp of the heteromeric channel may be slightly smaller than that of the homomeric channel because of the flickery gating, the error introduced by this difference is expected to be small. All experiments were performed at room temperature $\left(20^{\circ}-22^{\circ} \mathrm{C}\right)$. Values are given as mean + SEM .

\section{RESULTS}

\section{Primary structure of CNG6}

To identify new members of the CNG channel family, we performed a BLAST search of the EST database using the CNG4 protein as a query sequence. We retrieved the human EST HSA12972, encoding part of a new putative CNG channel that was designated CNG6. A 686 bp fragment was amplified from rat retina by RT-PCR using a pair of degenerate primers derived from EST HSA12972 and a portion of the cyclic nucleotide binding domain (CNBD) that is highly conserved among mammalian CNG channels. The full-length sequence of CNG6 was cloned from mouse retina by using a combination of cDNA library screening and RACE techniques. The sequence of murine CNG6 (mCNG6) consists of $4710 \mathrm{bp}$ and contains an open reading frame coding for a protein of 694 amino acids with a molecular mass of $80 \mathrm{kDa}$ (Fig. $1 A$ ). The predicted protein has the hallmark features of $\mathrm{CNG}$ channels, namely six transmembrane segments (S1-S6), a pore region $(\mathrm{P})$, and a CNBD in the $\mathrm{C}$ terminus. Within the $\mathrm{CNG}$ channel family, CNG6 is most closely related to the CNG4 $\beta$ subunit (47\% sequence identity at

and the CNBD are underlined. Gaps in the sequences are represented by dashes. Arrowheads in the N terminus of mCNG6 indicate the region corresponding to probe c used for in situ hybridization. Arrows mark the sequence corresponding to the EST HSA12972. An asterisk indicates the methionine at position 337 in the sequence of CNG6 that was replaced by leucine in the CNG6 expression vector. The sequence of mCNG6 is available from the European Molecular Biology Laboratory database under the accession number AJ243572. B, Phylogenetic tree of the mammalian CNG channel subunits. The tree was calculated based on the pairwise comparison with the transmembrane domains and the cyclic nucleotide binding domain of the respective subunits. The sequences are derived from mouse [CNG1 (Pittler et al., 1992); CNG3 (Biel et al., 1999b); CNG6 (this paper)] or rat [CNG2 (Dhallan et al., 1990); CNG4 (Sautter et al., 1998); CNG5 (Bradley et al., 1994)].
A

ICNG4, 3 MAKPGLNMELNRLVQDQPPGQEGPRPGPPNPABHLPNVPSYRPATTRIPV 50 MCNG6 MLKSITVKFNKVNPMEGRMEKKLCPNLSSLS 31 ICNG4.3 LVSRRTALSNSNFTKEIRSS IRR LVPATKEHPELQVEDTDAEAGA IPEE 100

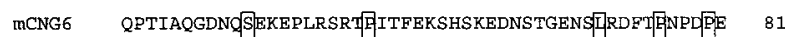
ICNG4 .3 TIPPPERPPUSPAKSDTLAU ESAATHRKKLPSQDDEAEE[KALSEAES 150

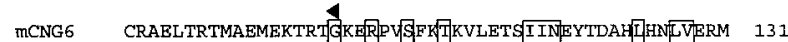
rCNG4.3 ---VAWSDPTTPQEADGEDRAAAS- -TASQNSA I INP-.--RLQELVKMF 1.90

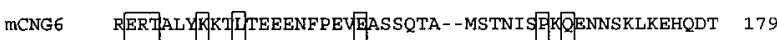
rCNG4.3 KERTEKVKEXLIDPDVTSD ESSPKPSPAKKAPDSA EA GKPAEAEAAEEEH 240

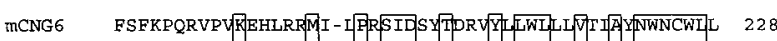

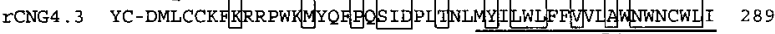
S1

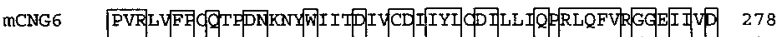

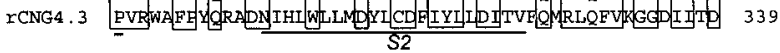

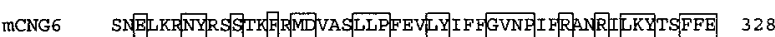

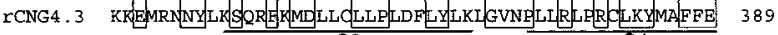

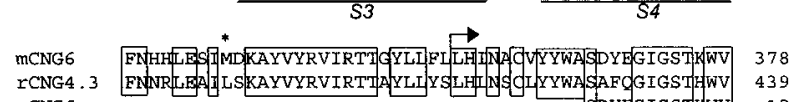
rCNG6 SOSEGIGSINWV 12

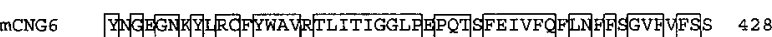

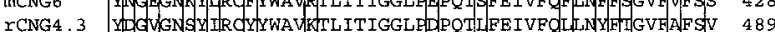
ICNG4.3 YMGYGNSY IROY

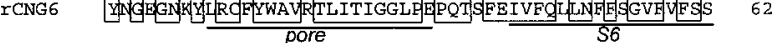

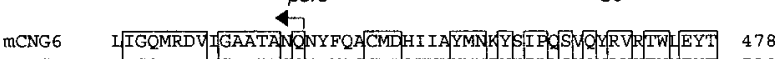

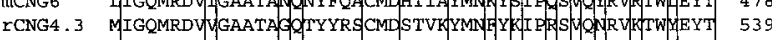

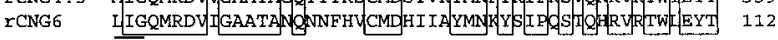

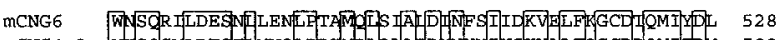

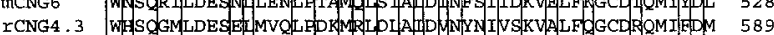

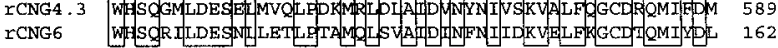
MCNG6 TH RLXST IYLEGDFVCKKGEIGW EMYI TNHG VOVLGGFDGA ICNG4.3 LWRLA SVVYYLPAD YVCKKGEIGR EMY I IQA GOVOVLGGPDGKA VLVTLKA 639 ICNG6 EIRIKSTIYIDGD FVCKKGEIGREMYIIKA G VOVLGGPDGAVVLVTLKA 212 CNBD

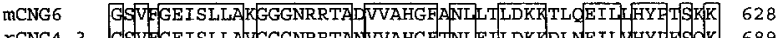

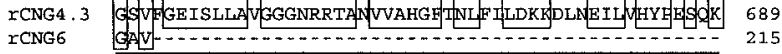

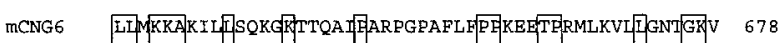

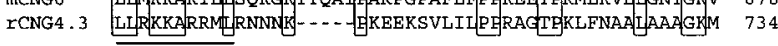
mCNG6 D-1.--DIGPID---LEGKRKTTTQKstop rCNG4.3 GPRGAKGGL LAH LRAR LKELAALEAAARQQQLLEQAKSSQEAGGEEGSGA 784 RCNG4.3 TDQPAPQEPSEPKEPPEPPAPSSPPPASAKPEGSTEEAAGPPEPSVRIRV 834 rCNG4.3 SPGPDPGEQTLSVEMLEEKKEEVESTOP 858

B
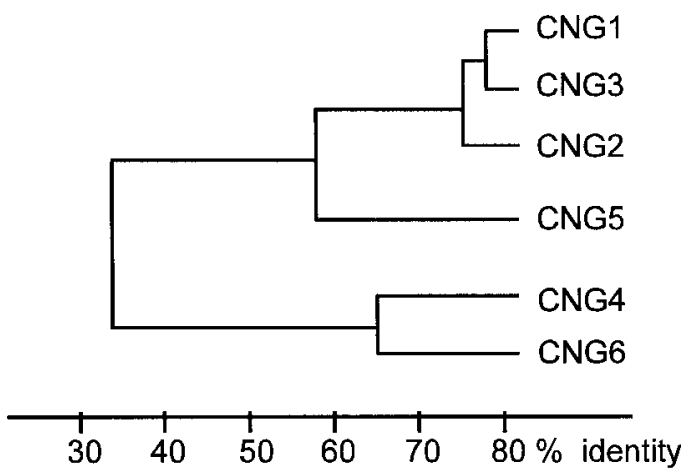

Figure 1. Primary structure of murine CNG6. A, Alignment of the amino acid sequence of mCNG6 with rCNG4.3 and a partial sequence of rCNG6 (the prefix indicates the species: $m=$ mouse; $r=$ rat). Amino acids identical between mCNG6 and rCNG4.3 or all three proteins are boxed. The putative transmembrane segments (S1-S6), the pore region, 


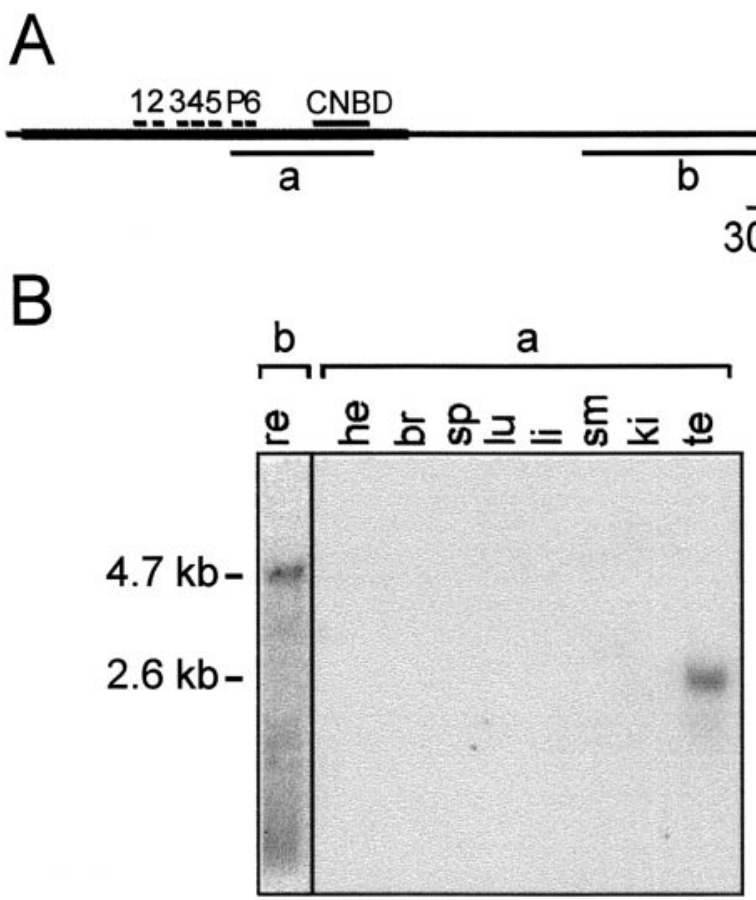

Figure 2. Expression of CNG6 transcripts in mouse tissues. $A$, Scheme of the mCNG6 cDNA. The protein coding region of CNG6 is represented by a box. The transmembrane segments $(1-6)$, the pore $(P)$, and the CNBD are indicated. The $3^{\prime}$ and $5^{\prime}$ untranslated sequences are shown by a thin line. The location of probes $a$ and $b$ used for Northern analysis are indicated below the sequence. $B$, Northern analysis of CNG6 expression. First lane, Left, Six micrograms of poly $\left(\mathrm{A}^{+}\right)$RNA isolated from mouse eyes was hybridized with probe $b$. Right blot, A mouse multiple tissue blot (Clontech) was analyzed with probe $a$. Each lane contained $\sim 2 \mu \mathrm{g}$ of poly $\left(\mathrm{A}^{+}\right)$RNA from the following tissues: heart, brain, spleen, lung, liver, skeletal muscle, kidney, testis. Audioradiographic exposure was for $7 \mathrm{~d}$ at $-70^{\circ} \mathrm{C}$.

the amino acid level). In contrast, CNG6 has only a weak homology with the CNG channel $\alpha$ subunits CNG1-3 (35\% identity) and with the CNG5 $\beta$ subunit (33\%) (Fig. $1 B$ ). The homology between CNG6 and CNG4 is most pronounced in the transmembrane core and the CNBD (65\% sequence identity). The pore region of CNG6 is clearly related to that of CNG4. In both subunits, the glutamate residue that forms a high-affinity binding site for $\mathrm{Ca}^{2+}$ in $\mathrm{CNG}$ channel $\alpha$ subunits and controls channel gating and ion permeation (Root and MacKinnon, 1993; Eismann et al., 1994) is replaced by a glycine residue (position 402 in CNG6). The primary sequences of CNG4 and CNG6 diverge most strongly from each other in their respective cytoplasmic $\mathrm{N}$ termini. In particular, CNG6 does not contain a GARP domain (Sugimoto et al., 1991) that is present in the extended cytosolic $\mathrm{N}$ terminus of the CNG4 subunit (Körschen et al., 1995; Ardell et al., 1996; Colville and Molday, 1996; Sautter et al., 1997). In addition, the calcium-calmodulin ( $\mathrm{CaM}$ )-binding site that has been identified in the $\mathrm{N}$ terminus of $\mathrm{CNG} 4\left(\mathrm{~A}_{168}-\mathrm{D}_{209}\right.$ of CNG4.3) (Grunwald et al., 1998; Weitz et al., 1998) is only poorly conserved in CNG6 (30\% sequence identity). A sequence corresponding to the C-terminal CaM-binding site of CNG4 (Grunwald et al., 1998; Weitz et al., 1998) is completely missing in CNG6. There is also no evidence for a CaM-binding site similar to that found in the olfactory CNG channel $\alpha$ subunit (Liu et al., 1994).

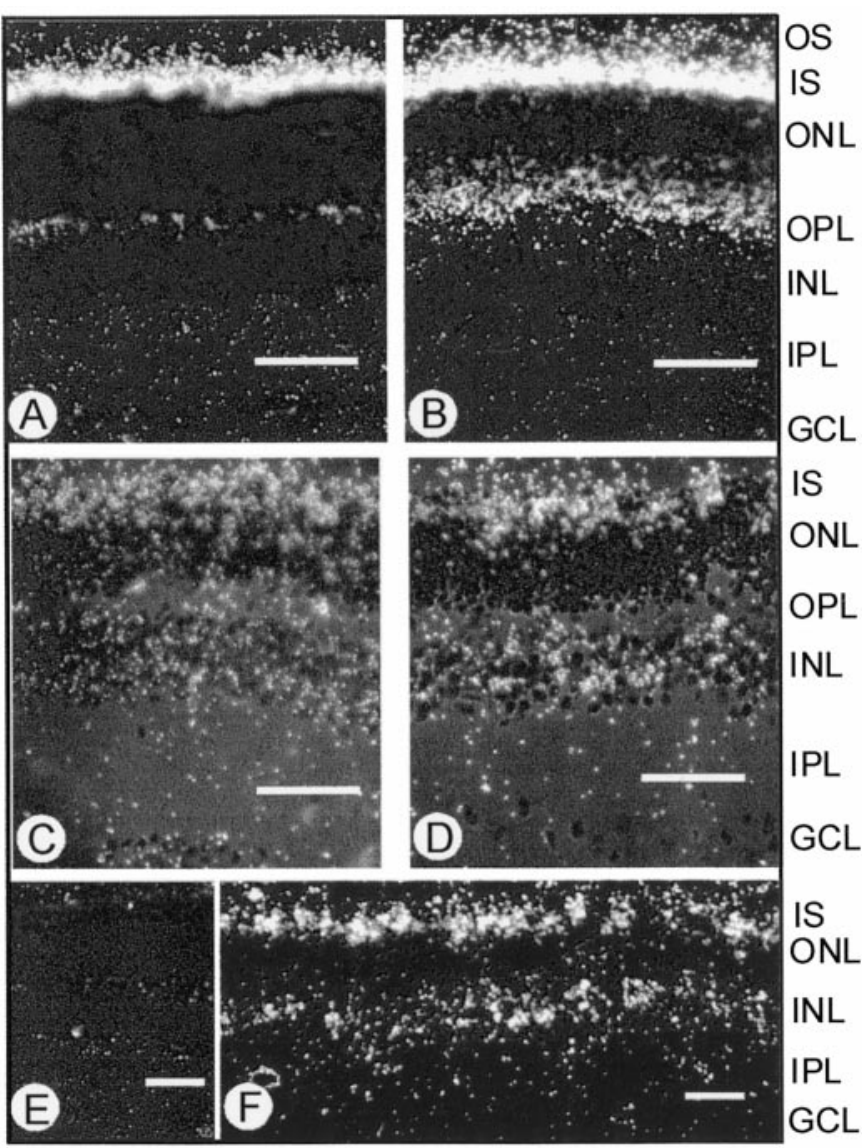

Figure 3. Expression of $\mathrm{CNG}$ channel subunits in mouse retina as determined by in situ hybridization. Shown are dark-field photographs of cryosections of mouse retina hybridized with ${ }^{35} \mathrm{~S}$-labeled antisense riboprobes specific for CNG1 $(A), \mathrm{CNG} 4(B), \mathrm{CNG} 3(C)$, and CNG6 (probe c) $(D, F)$ and with a sense riboprobe specific for CNG6 $(E)$. CNG1- and CNG4-specific probes detected strong expression in retinal photoreceptors as indicated by the reaction product localized to the inner segments $(I S)$ of these cells. CNG3- and CNG6-specific probes only labeled a subset of photoreceptors and also hybridized weakly with the inner nuclear layer $(I N L)$. A sense probe directed against CNG6 produced no signal $(E)$. Exposure to film emulsion was 2 weeks for CNG1 and CNG4 and 5 weeks for CNG3 and CNG6. OS, Outer segment; $I S$, inner segment; $O N L$, outer nuclear layer; $I P L$, inner plexiform layer; $O P L$, outer plexiform layer; $G C L$, ganglion cell layer. Scale bars, $30 \mu \mathrm{m}$.

\section{Northern blot analysis of CNG6 expression}

To examine the tissue expression of CNG6 mRNA, we designed probes $\mathrm{a}$ and $\mathrm{b}$ that were derived from the coding region (probe a) and the $3^{\prime}$ untranslated region (probe b) of the CNG6 cDNA, respectively (Fig. $2 A$ ). Probe b detected a $4.7 \mathrm{~kb}$ transcript in mouse retina (Fig. $2 B$ ). A transcript of the same size was also found with probe a (data not shown). The size of the CNG6 mRNA is in good agreement with the length of the cloned cDNA (4710 bp), indicating that the cloned cDNA covers the full-length sequence of the mRNA. Expression of CNG6 mRNA was also observed in testis. However, the mRNA detected in testis was significantly smaller $(2.6 \mathrm{~kb})$ than the retinal isoform and may represent an alternatively spliced transcript of the CNG6 gene.

\section{Expression of CNG channel transcripts in mouse retina}

The retinal localization of CNG6 and other CNG channel transcripts was investigated by performing in situ hybridizations of ${ }^{35}$ S-labeled antisense RNA probes to cryostat sections (Fig. 3). 
Probes directed against the rod photoreceptor $\alpha$ subunit CNG1 (Fig. $3 A$ ) and $\beta$ subunit CNG4 (Fig. $3 B$ ) strongly and uniformly labeled the inner segment layer (IS) of photoreceptors. This result is consistent with the expression of both subunits in rods that in mice make up $>90 \%$ of all photoreceptors. Surprisingly, both probes also labeled the outer plexiform layer (OPL) where the synapses of photoreceptors are located. The physiological relevance of the presence of mRNA in the OPL is not known so far. The CNG6-specific probe (probe c) predominantly detected expression in retinal photoreceptors and also labeled the inner nuclear cell layer (Fig. 3D,F). However, in contrast to CNG1 and CNG4, the transcript of CNG6 was only present in a minor subset of the photoreceptors. A very similar clustered expression pattern was found with hybridization of the CNG3-specific probe (Fig. $3 C$ ). We performed two controls to confirm the specificity of the in situ hybridizations. (1) Hybridization with a second probe directed against CNG6 (probe d, see Materials and Methods) yielded the same expression pattern as detected by probe $\mathrm{c}$ (data not shown). (2) A sense probe for CNG6 did not hybridize to retinal sections (Fig. $3 E$ ). Sense probes for $\mathrm{CNG} 1, \mathrm{CNG} 3$, and CNG4 also did not label retinal sections (data not shown). Taken together, the expression level and localization of the CNG6 message corresponded well with the expression of $\mathrm{CNG} 3$, whereas it was clearly different from the expression of CNG1 and CNG4.

\section{Functional expression of CNG6 in HEK293 cells}

As anticipated from the structural relationship of CNG6 to the rod photoreceptor $\beta$ subunit, CNG6 did not produce a functional CNG channel when expressed in HEK293 cells. Because in situ hybridizations indicated that CNG6 was colocalized with CNG3, we co-transfected HEK293 cells with equimolar amounts of cDNAs for both subunits. Currents measured from excised inside-out patches of CNG3/CNG6 differed in several aspects from the current induced by $\mathrm{CNG} 3$ alone, indicating that CNG6 is a modulatory $\mathrm{CNG}$ channel subunit. The cGMP-induced single-channel current of the CNG3 channel was characterized by the presence of both brief $(<1 \mathrm{msec})$ and considerably longer ( $\sim 10 \mathrm{msec}$ or longer) openings (Fig. $4 A$ ). Instead, similar to the native channel from vertebrate photoreceptors (Haynes and Yau, 1990; Quandt et al., 1991), patches containing the CNG3/CNG6 channel $(n=6)$ always revealed bursts of flickery activity consisting of opening events lasting $\sim 1 \mathrm{msec}$ or less. The heteromeric channel (Fig. $4 B$ ) had a single-channel conductance of $\sim 42 \mathrm{pS}$, which was comparable to that of the CNG3 channel (46 pS).

Like the rod photoreceptor $\beta$ subunit, CNG6 influenced the interaction of the $\mathrm{CNG}$ channel with $\mathrm{Ca}^{2+}$. Figure 5 shows the macrosopic current-voltage relations for the CNG3 and the CNG3/CNG6 channel at a saturating cGMP concentration in the presence of $2 \mathrm{mM} \mathrm{Ca}^{2+}$ on the extracellular side of the membrane. Under these conditions the outward rectification resulting from divalent blockage was less pronounced in the heteromeric channel than in the homomeric channel.

L-cis diltiazem is a known blocker of native CNG channels of photoreceptor outer segments (Stern et al., 1986; Haynes, 1992). We therefore tested the sensitivity of homomeric and heteromeric channels for this drug (Fig. 6). The current amplitude of the homomeric channel activated by a saturating cGMP concentration was not significantly altered by the addition of $10 \mu \mathrm{M}$ diltiazem on the intracellular side (Fig. $6 A, C$ ). In contrast, the current of the heteromeric channel was blocked by L-cis diltiazem under the same conditions in a time- and voltage-dependent
A
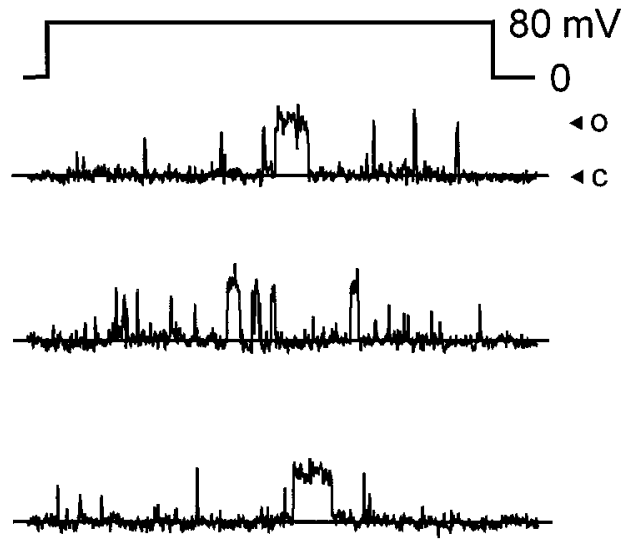

$50 \mathrm{~ms}$

$2 \mathrm{pA}$

B
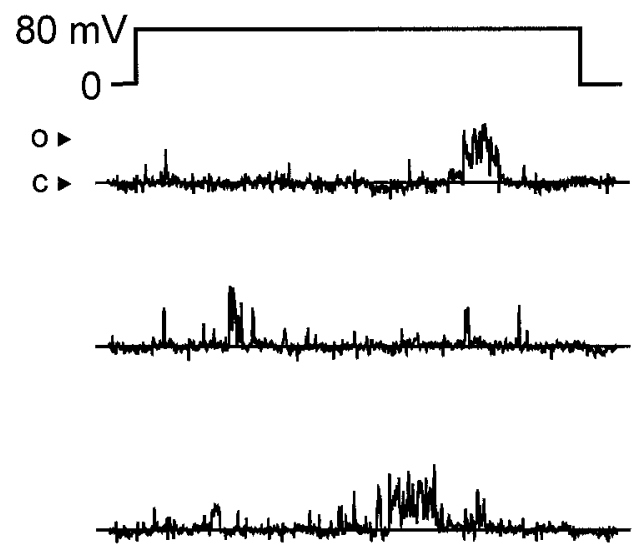

Figure 4. Single-channel activity of homomeric and heteromeric channels. The recordings show single-channel currents from an inside-out patch of HEK293 cells transfected either with an expression vector encoding CNG3 $(A)$ or equimolar amounts of expression plasmids encoding CNG3 and CNG6 $(B)$. The currents were evoked by $1 \mu \mathrm{M}$ cGMP at a membrane potential of $+80 \mathrm{mV}$. $o$, Open channel; $c$, closed channel.

manner (Fig. $6 B, D$ ). At $+80 \mathrm{mV}, 10 \mu \mathrm{M}$ diltiazem reduced the current amplitude by $65.0 \pm 2.5 \%(n=12)$, whereas at negative voltages the block was significantly less pronounced (inhibition of current amplitude by $22.8 \pm 3.9 \%$ at $-80 \mathrm{mV} ; n=12)$. Thus, the characteristics of the L-cis diltiazem block of the CNG3/CNG6 channel are in agreement with the blocking parameters (i.e., inhibitory concentration range, kinetics, and voltagedependence) described for the native cone channel (Haynes, 1992).

We next studied the influence of CNG6 on the channel activation by cyclic nucleotides. As shown by the current traces in Figure $7 A$, cAMP is a partial agonist of the CNG3 channel, activating only $\sim 15 \%$ of the current that was activated by a saturating cGMP concentration $\left(I_{\mathrm{cAMP}} / I_{\mathrm{cGMP}}=0.14 \pm 0.02 ; n=\right.$ 11). In the heteromeric $\mathrm{CNG} 3 / \mathrm{CNG} 6$ channel (Fig. $7 B$ ), the maximal cAMP current was significantly elevated and made up $\sim 60 \%$ of the maximal cGMP-activated current $\left(I_{\mathrm{cAMP}} / I_{\mathrm{cGMP}}=\right.$ $0.58 \pm 0.02 ; n=13)$. In addition to increasing the relative efficacy of cAMP, CNG6 also altered the time-dependence of the mac- 


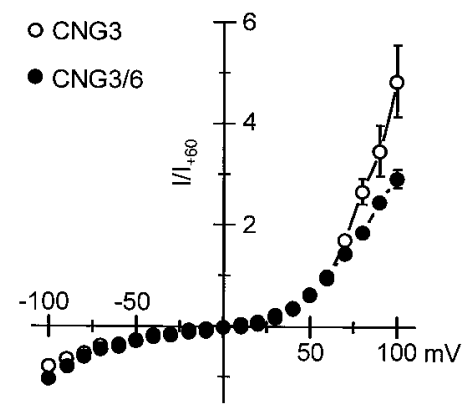

Figure 5. Current-voltage relations of $\mathrm{CNG} 3$ and CNG3/CNG6 channels in the presence of $2 \mathrm{~mm}$ extracellular $\mathrm{Ca}^{2+}$. The currents were activated by $300 \mu \mathrm{M}$ cGMP and normalized to the current at $+60 \mathrm{mV}$ $\left(I_{+60}\right)$. The points represent means \pm SEM from four (CNG3) or six (CNG3/CNG6) patches.

roscopic current. At positive voltages, the cGMP-activated current of the CNG3/CNG6 channel revealed an initial decay with characteristic relaxation to a plateau level. The initial decay after addition of cAMP was very small and was also not observed at negative potentials (Fig. $6 \mathrm{~B}$, bottom trace). In contrast to its prominent effect on the cAMP efficacy, coexpression of CNG6 did not alter the apparent affinities for either cyclic nucleotides (Fig. 7C).

According to allosteric models of $\mathrm{CNG}$ channel activation (Tibbs et al., 1997; Paoletti et al., 1999), an increase in cyclic nucleotide efficacy can result from a decrease in the energetic cost of the intrinsic opening reaction of the unliganded channel. To examine whether such a mechanism holds true for the increase of the cAMP efficacy evoked by the CNG6 subunit, we measured the spontaneous channel openings in inside-out patches containing either homomeric or heteromeric channels. In HEK293 cells transfected with an empty expression vector, a 42-46 pS conduc-

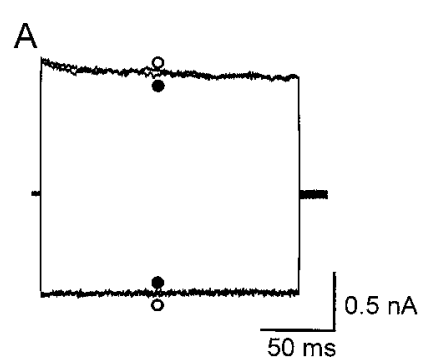

C
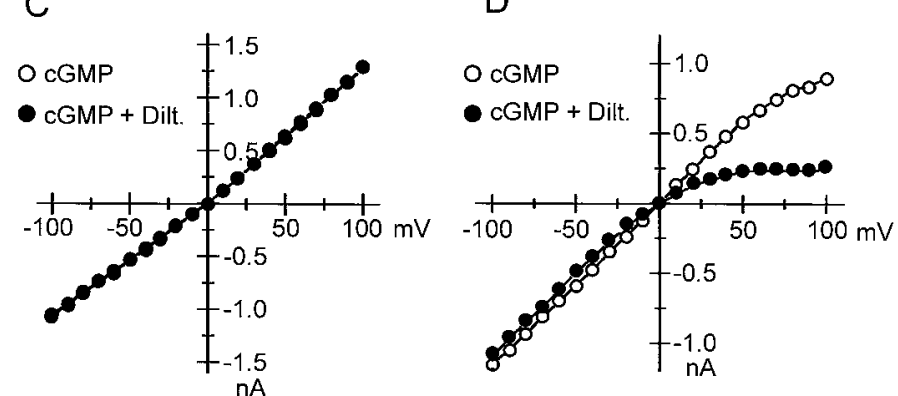

Figure 6. Sensitivity of homomeric and heteromeric channels to L-cis diltiazem. Current traces of the CNG3 $(A)$ and the CNG3/CNG6 channels $(B)$ induced at $\pm 80 \mathrm{mV}$ in the absence $(\bigcirc)$ and presence $(\bullet)$ of 10 $\mu \mathrm{M}$ intracellular L-cis-diltiazem (Dilt.). $C, D$, Steady-state current-voltage relations of the CNG3 $(C)$ and CNG3/CNG6 currents $(D)$ in the presence and absence of $10 \mu \mathrm{M} \mathrm{L}$-cis diltiazem. cGMP (300 $\mu \mathrm{M})$ was used to activate the channels in $A-D$.
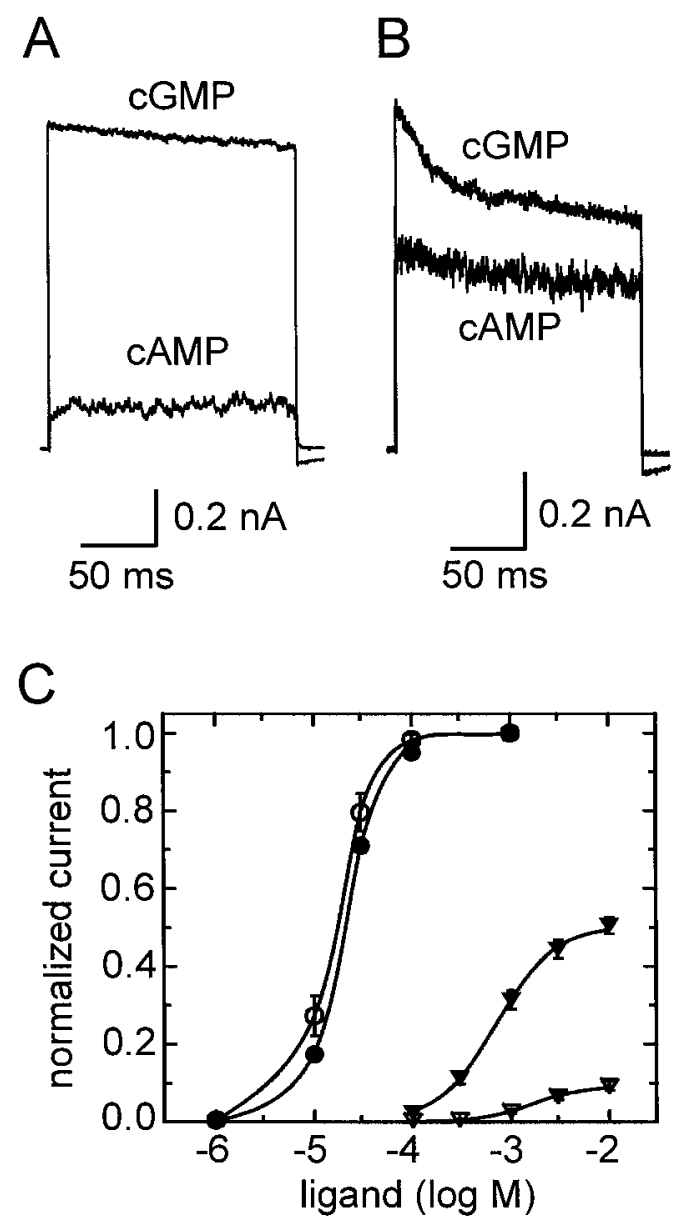

Figure 7. Increase of cAMP efficacy induced by CNG6. Currents were induced at $+80 \mathrm{mV}$ in excised inside-out patches containing either CNG3 $(A)$ or CNG3/CNG6 $(B)$ by a saturating concentration of cGMP $(1 \mathrm{mM})$ or cAMP $(10 \mathrm{mM})$. Note that the initial decay of the cGMP current in $B$ does not occur in the homomeric channel $(A)$. $C$, Dose-response curves for CNG3 (open symbols) and CNG3/CNG6 (closed symbols) currents induced by cGMP (circles) or cAMP (triangles). Curves were normalized to the response at $1 \mathrm{mM}$ of cGMP. Each point represents the mean \pm SEM from five to seven patches. The solid lines are best fits calculated by the Hill equation (see Materials and Methods). Concentrations are as follows (in $\mu \mathrm{M}$ ): CNG3, cGMP: $K_{\mathrm{a}}=16.6 \pm 2.2, \nu=2.4 \pm 0.1(n=6)$; cAMP: $K_{\mathrm{a}}=1690 \pm 70, \nu=1.8 \pm 0.1(n=5)$; CNG3/CNG6, cGMP: $K_{\mathrm{a}}=20.2 \pm 0.6, \nu=2.2 \pm 0.1(n=7) ;$ cAMP: $K_{\mathrm{a}}=735 \pm 60, \nu=1.5 \pm$ $0.1(n=6)$.

tance comparable to that induced by expression of CNG3 or CNG3/CNG6 was not observed. Examples of spontaneous activity from an individual patch containing either CNG3 or CNG3/ CNG6 are illustrated in Figure 8, $A$ and $B$, respectively. Currents were recorded at $+80 \mathrm{mV}$ in the absence of ligand. It is evident that many more opening events occurred in the patch containing the CNG3/CNG6 channel than in the patch containing the CNG3 channel alone. The higher number of opening events did not simply reflect the presence of a higher number of channels in the CNG3/CNG6 patch. The maximal current induced by a saturating cGMP concentration was roughly the same in both patches (Fig. $8 C, D$ ), and both channels have a comparable single-channel conductance (Fig. 4A,B). The ratio between the spontaneous current and the maximal cGMP-activated current $\left(I_{\mathrm{sp}} / I_{\max }\right)$, as determined from six individual patches of cells expressing each channel was $2.1 \pm 0.3 \times 10^{-4}$ for the CNG3 channel and $2.7 \pm$ 


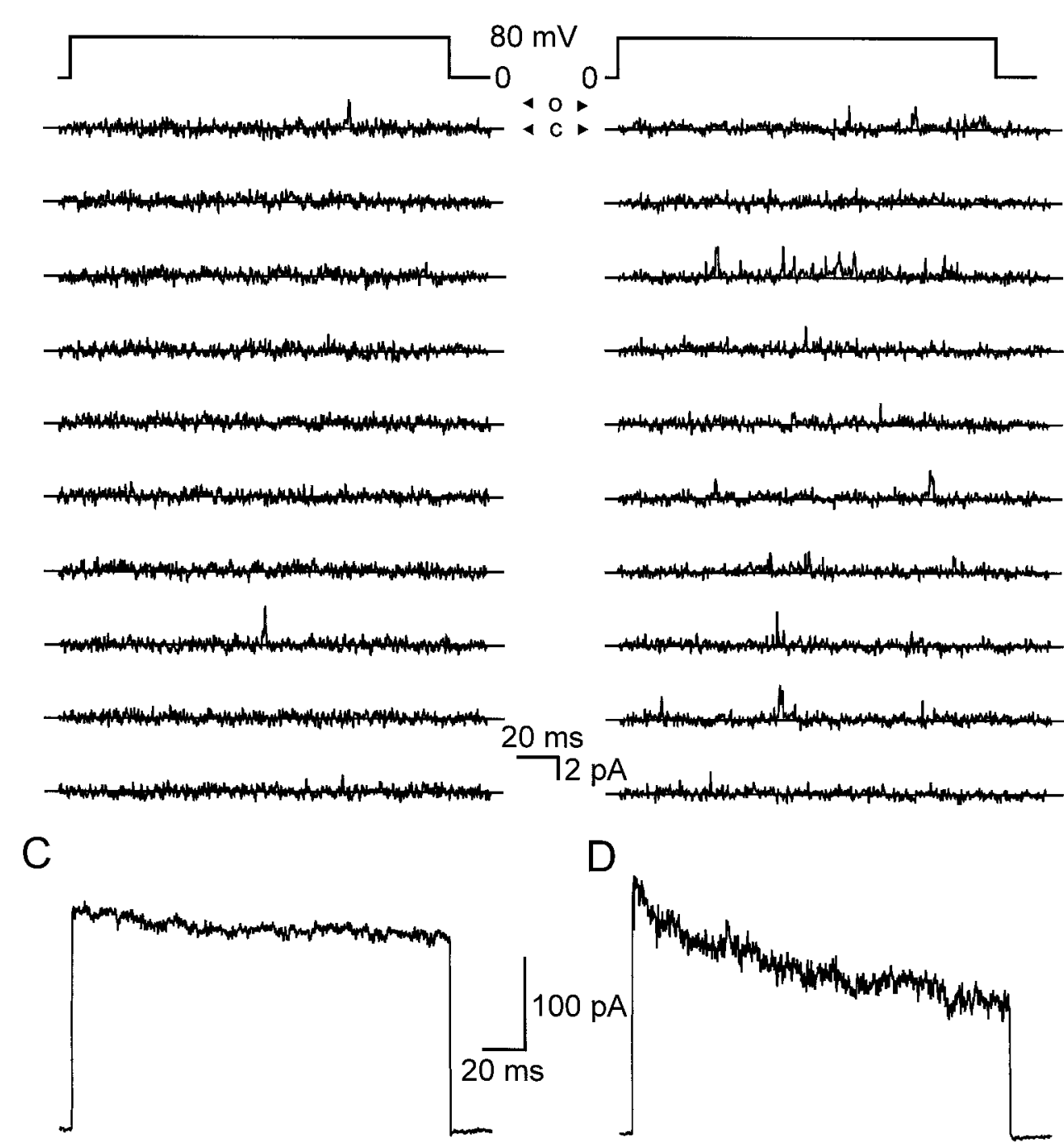

Figure 8. Ligand-independent openings of homomeric and heteromeric channels. In two individual patches containing approximately 60 channels of either CNG3 $(A)$ or CNG3/CNG6 $(B)$, currents were activated by applying $200 \mathrm{msec}$ pulses at $0.5 \mathrm{~Hz}$ from a holding potential of 0 to $+80 \mathrm{mV}$. For each patch 50 consecutive pulses, 10 of which are shown, were analyzed. The mean spontaneous current $\left(I_{\mathrm{sp}}\right)$ was defined as the average current measured from 50 pulses. After the ligandindependent activation, the patches were perfused with a saturating cGMP concentration and again depolarized to $+80 \mathrm{mV}$ to activate the maximal current $\left(I_{\max }\right)$ of the CNG3 $(C)$ and CNG3/CNG6 $(D)$ channel. o, Open channel; $c$, closed channel.

$0.7 \times 10^{-3}$ for the $\mathrm{CNG} 3 / \mathrm{CNG} 6$ channel. Thus, the heteromeric channel has an approximately 13 -fold higher spontaneous activity than the homomeric channel.

\section{DISCUSSION}

In this study we report the molecular cloning and functional expression of a new CNG channel subunit, CNG6, from murine retina. The phylogenetic analysis indicates that within the $\mathrm{CNG}$ channel family CNG6 is most closely related to the CNG4 $\beta$ subunit. Both subunits form a distinct branch of the phylogenetic tree that has separated from other $\mathrm{CNG}$ channels early during evolution. The structural similarity between CNG4 and CNG6 is seen mainly in the transmembrane segments, the ion-conducting pore region, and the $\mathrm{CNBD}$, whereas $\mathrm{C}$ and $\mathrm{N}$ termini are only poorly conserved between both proteins. Interestingly, unlike CNG4 the sequence of CNG6 does not contain a large GARP domain in the $\mathrm{N}$ terminus. In accordance with this finding, a GARP protein was not identified in cones, suggesting that GARP has a function that is specific to rods and absent in cones (Körschen et al., 1999). The CNG4 primary transcript is extensively spliced, resulting in various isoforms that differ from each other in the N terminus (Körschen et al., 1995; Ardell et al., 1996; Sautter et al., 1998; Wiesner et al., 1998). So far we have no evidence for alternatively spliced isoforms of CNG6 in retina. However, the presence of a smaller CNG6 transcript in mouse testis points to the possibility that splice products of CNG6 may exists in other tissues.

In situ hybridization with CNG6-specific probes indicated that the expression level of CNG6 in retina is comparable with that of the cone CNG channel $\alpha$ subunit CNG3 but is very low with respect to the expression levels of rod photoreceptor subunits CNG1 and CNG4. In particular, the CNG6 transcript is similar to $\mathrm{CNG} 3$ in that it is only present in a small subset of photoreceptor cells. It has been demonstrated that CNG3 is exclusively expressed in cones (Bönigk et al., 1993; Weyand et al., 1994; Biel et al., 1999b) which represent only $\sim 3 \%$ of murine photoreceptors (Carter-Dawson and LaVail, 1979). Thus, the clustered expression of CNG6 would be consistent with the colocalization of this subunit with CNG3 in cones. Transcripts of CNG6 were also detected in the inner nuclear layer (INL) of the retina. This layer contains cell bodies of bipolar, amacrine, Müller glial, and horizontal cells (Wheater et al., 1987). There is evidence for the presence of a CNG channel in On-bipolar cells (Nawy and Jahr, 1990; Shiells and Falk, 1992). A putative cGMP-activated channel has also been detected in retinal Müller glial cells (Kusaka et al., 
1996). So far the primary sequence and subunit composition of the respective $\mathrm{CNG}$ channels have not yet been determined. The expression of the CNG6 transcript in the INL suggests that CNG6 may form a subunit of these channels.

The heterologous expression of CNG6 in HEK293 cells confirmed that CNG6 is a CNG channel $\beta$ subunit and that it associates with $\mathrm{CNG} 3$ to form a heteromeric $\mathrm{CNG}$ channel. As predicted from the primary structure analysis, CNG6 does not give rise to functional $\mathrm{CNG}$ channels when expressed alone. However, when coexpressed with CNG3 it confers various new channel properties that are not observed with the homomeric CNG3 channel but are characteristic of native cone photoreceptor channels. These new properties include the induction of single-channel flickering, the increase of the sensitivity for L-cis diltiazem, and the weakening of the outward rectification induced by $\mathrm{Ca}^{2+}$. In addition, heteromeric CNG3/CNG6 channels differ from homomeric channels by a significantly higher cAMP efficacy and a voltage-dependent transient peak of the cGMP current. To our knowledge, these two properties have not yet been described for native cone channels. However, cone channels have been studied only in two species of fish (Haynes and Yau, 1985, 1990; Picones and Korenbrot, 1994). Thus, it has not been determined whether the observed novel properties are intrinsic to the heterologously expressed CNG3/CNG6 channel or whether they reflect the species difference between fish and mouse.

The CNG6 subunit induces a significant increase of the spontaneous channel activity in the absence of cyclic nucleotides. A high ligand-independent activity was also detected in native cone photoreceptors of fish (Picones and Korenbrot, 1995). In fish cones the spontaneous current was $\sim 4.5 \%$ of that measured under saturating cGMP concentrations, being approximately $15-$ fold higher than observed for the murine CNG3/CNG6 channel. This difference may be caused by the intrinsic properties of the respective CNG channel subunits in fish and mouse. Alternatively, the spontaneous activity could be regulated by cellular factors that are present in cones but absent in HEK293 cells.

Taken together, our results demonstrate that coexpression of CNG6 with the CNG3 channel restores various, if not all, functional properties of the native cone photoreceptor channel that are not present in the homomeric CNG3 channel. This finding, together with the data from in situ hybridization, strongly suggests that $\mathrm{CNG} 3$ and CNG6 constitute subunits of the native cone photoreceptor channel. In cell types other than cone photoreceptors, CNG3 may be associated with other $\beta$ subunits. For example, it was shown that in bovine sperm, CNG3 is colocalized with specific splice variants of the CNG4 subunit (Wiesner et al., 1998). In heterologous expression systems, CNG3 and CNG4 are able to form a heteromeric CNG channel (Biel et al., 1996). It is thus tempting to speculate that depending on the respective tissue, cell type, or species, different $\beta$ subunits are used to generate various heteromeric CNG channels with distinct functional properties and physiological functions.

\section{REFERENCES}

Ardell MD, Aragon I, Oliveira L, Porche GE, Burke E, Pittler SJ (1996) The $\beta$ subunit of human rod photoreceptor CGMP-gated cation channel is generated from a complex transcription unit. FEBS Lett 389:213-218.

Barnstable CJ, Wei JY (1995) Isolation and characterization of the $\alpha$-subunit of the rat rod photoreceptor cGMP-gated cation channel. J Mol Neurosci 6:289-302.

Baylor D (1996) How photons start vision. Proc Natl Acad Sci USA 93:560-565.
Biel M, Zong X, Distler M, Bosse E, Klugbauer N, Murakami M, Flockerzi V, Hofmann F (1994) Another member of the cyclic nucleotide-gated channel family, expressed in testis, kidney, and heart. Proc Natl Acad Sci USA 91:3505-3509.

Biel M, Zong X, Ludwig A, Sautter A, Hofmann F (1996) Molecular cloning and expression of a modulatory subunit of the cyclic nucleotidegated cation channel. J Biol Chem 271:6349-6355.

Biel M, Zong X, Ludwig A, Sautter A, Hofmann F (1999a) Structure and function of cyclic nucleotide-gated channels. Rev Physiol Biochem Pharmacol 135:151-171.

Biel M, Seeliger M, Pfeiffer A, Kohler K, Gerstner A, Ludwig A, Jaissle G, Fauser S, Zrenner E, Hofmann F (1999b) Selective loss of cone function in mice lacking the cyclic nucleotide-gated channel CNG3. Proc Natl Acad Sci USA 96:7553-7557.

Bönigk W, Altenhofen W, Müller F, Dose A, Illing M, Molday RS, Kaupp UB (1993) Rod and cone photoreceptor cells express distinct genes for cGMP-gated channels. Neuron 10:865-877.

Bönigk W, Bradley J, Müller F, Sesti F, Boekhoff I, Ronnett GV, Kaupp UB, Frings S (1999) The native rat olfactory cyclic nucleotide-gated channel is composed of three distinct subunits. J Neurosci 19:5332-5347.

Bradley J, Li J, Davidson N, Lester HA, Zinn K (1994) Heteromeric olfactory cyclic nucleotide-gated channels: a new subunit that confers increased sensitivity to cAMP. Proc Natl Acad Sci USA 91:8890-8894.

Carter-Dawson LD, LaVail MM (1979) Rods and cones in the mouse retina. I. Structural analysis using light and electron microscopy. J Comp Neurol 188:245-276.

Chen TY, Peng YW, Dhallan RS, Ahamed B, Reed RR, Yau KW (1993) A new subunit of the cyclic nucleotide-gated cation channel in retinal rods. Nature 362:764-767.

Colville CA, Molday RS (1996) Primary structure and expression of the human beta-subunit and related proteins of the rod photoreceptor cGMP-gated channel. J Biol Chem 271:32968-32974.

Dhallan RS, Yau KW, Schrader KA, Reed RR (1990) Primary structure and functional expression of a cyclic nucleotide-activated channel from olfactory neurons. Nature 347:184-187.

Eismann E, Müller F, Heinemann SH, Kaupp UB (1994) A single negative charge within the pore region of a cGMP-gated channel controls rectification, $\mathrm{Ca} 2+$ blockage, and ionic selectivity. Proc Natl Acad Sci USA 91:1109-1113.

Finn JT, Grunwald ME, Yau KW (1996) Cyclic nucleotide-gated ion channels: an extended family with diverse functions. Annu Rev Physiol 58:395-426.

Gordon S, Zagotta WN (1995) Subunit interactions in coordination of $\mathrm{Ni}^{2+}$ in cyclic nucleotide-gated channels. Proc Natl Acad Sci USA 92:10222-10226.

Grunwald ME, Yu WP, Yu HH, Yau KW (1998) Identification of a domain on the $\beta$-subunit of the rod cGMP-gated cation channel that mediates inhibition by calcium-calmodulin. J Biol Chem 273:9148-9157.

Haynes LW (1992) Block of the cyclic GMP-gated channel of vertebrate rod and cone photoreceptors by l-cis-diltiazem. J Gen Physiol 100:783-801.

Haynes LW, Yau KW (1985) Cyclic GMP-sensitive conductance in outer segment membrane of catfish cones. Nature 317:61-64.

Haynes LW, Yau KW (1990) Single-channel measurement from the cyclic GMP-activated conductance of catfish retinal cones. J Physiol (Lond) 429:451-481.

Kaupp UB, Niidome T, Tanabe T, Terada S, Bönigk W, Stühmer W, Cook NJ, Kangawa K, Matsuo H, Hirose T, Miyata T, Numa S (1989) Primary structure and functional expression from complementary DNA of the rod photoreceptor cyclic GMP-gated channel. Nature 342:762-766.

Kohl S, Marx T, Giddings I, Jagle H, Jacobson SG, Apfelstedt SE, Zrenner E, Sharpe LT, Wissinger B (1998) Total colour blindness is caused by mutations in the gene encoding the alpha-subunit of the cone photoreceptor cGMP-gated cation channel. Nat Genet 19:257-259.

Körschen HG, Illing M, Seifert R, Sesti F, Williams A, Gotzes S, Colville C, Müller F, Dose A, Godde M, Molday L, Kaupp UB, Molday RS (1995) A $240 \mathrm{kDa}$ protein represents the complete $\beta$ subunit of the cyclic nucleotide-gated channel from rod photoreceptor. Neuron 15:627-636.

Körschen HG, Beyermann M, Müller F, Heck M, Vantler M, Koch KW, Kellner R, Wolfrum U, Bode C, Hofmann KP, Kaupp UB (1999) 
Interaction of glutamic-acid-rich proteins with the cGMP signalling pathway in rod photoreceptors. Nature 400:761-766.

Kusaka S, Dabin I, Barnstable CJ, Puro DG (1996) cGMP-mediated effects on the physiology of bovine and human retinal Müller (glial) cells. J Physiol (Lond) 497:725-729.

Liman ER, Buck LB (1994) A second subunit of the olfactory cyclic nucleotide-gated channel confers high sensitivity to cAMP. Neuron 13:611-621.

Liu DT, Tibbs GR, Siegelbaum SA (1996) Subunit stoichiometry of cyclic nucleotide-gated channels and effects of subunit order on channel function. Neuron 16:983-990.

Liu M, Chen TY, Ahamed B, Li J, Yau KW (1994) Calcium-calmodulin modulation of the olfactory cyclic nucleotide-gated cation channel. Science 266:1348-1354.

Ludwig A, Flockerzi V, Hofmann F (1997) Regional expression and cellular localization of the $\alpha 1$ and $\beta$ subunits of high voltage-activated calcium channels in rat brain. J Neurosci 17:1339-1349.

Ludwig J, Margalit T, Eismann E, Lancet D, Kaupp UB (1990) Primary structure of cAMP-gated channel from bovine olfactory epithelium. FEBS Lett 270:24-29.

Nawy S, Jahr CE (1990) Suppression by glutamate of cGMP-activated conductance in retinal bipolar cells. Nature 346:269-271.

Paoletti P, Young EC, Siegelbaum SA (1999) C-Linker of cyclic nucleotide-gated channels controls coupling of ligand binding to channel gating. J Gen Physiol 113:17-34.

Picones A, Korenbrot JI (1994) Analysis of fluctuations in the cGMPdependent current of cone photoreceptor outer segments. Biophys $\mathbf{J}$ 66:360-365.

Picones A, Korenbrot JI (1995) Spontaneous, ligand-independent activity of the cGMP-gated ion channels in cone photoreceptors of fish. J Physiol (Lond) 485:699-714.

Pittler SJ, Lee AK, Altherr MR, Howard TA, Seldin MF, Hurwitz RL, Wasmuth JJ, Baehr W (1992) Primary structure and chromosomal localization of human and mouse rod photoreceptor cGMP-gated cation channel. J Biol Chem 267:6257-6262.

Quandt FN, Nicol GD, Schnetkamp PP (1991) Voltage-dependent gating and block of the cyclic-GMP-dependent current in bovine rod outer segments. Neuroscience 42:629-638.

Root MJ, MacKinnon R (1993) Identification of an external divalent cation-binding site in the pore of a cGMP-activated channel. Neuron 11:459-466.

Sautter A, Biel M, Hofmann F (1997) Molecular cloning of cyclic nucleotide-gated cation channel subunits from rat pineal gland. Brain Res Mol Brain Res. 48:171-175.

Sautter A, Zong X, Hofmann F, Biel M (1998) An isoform of the rod photoreceptor cyclic nucleotide-gated channel beta subunit expressed in olfactory neurons. Proc Natl Acad Sci USA 95:4696-4701.

Schild D, Restrepo D (1998) Transduction mechanisms in vertebrate olfactory receptor cells. Physiol Rev 78:429-466.

Shammat IM, Gordon SE (1999) Stoichiometry and arrangement of subunits in rod cyclic nucleotide-gated channels. Neuron 23:809-819.

Shiells RA, Falk G (1992) Properties of the cGMP-activated channel of retinal on-bipolar cells. Proc R Soc Lond B Biol Sci 247:21-25.

Stern JH, Kaupp UB, MacLeish PR (1986) Control of the lightregulated current in rod photoreceptors by cyclic GMP, calcium, and 1-cis-diltiazem. Proc Natl Acad Sci USA 83:1163-1167.

Sugimoto Y, Yatsunami K, Tsujimoto M, Khorana HG, Ichikawa A (1991) The amino acid sequence of a glutamic acid-rich protein from bovine retina as deduced from the cDNA sequence. Proc Natl Acad Sci USA 88:3116-3119.

Tibbs GR, Goulding EH, Siegelbaum SA (1997) Allosteric activation and tuning of ligand efficacy in cyclic-nucleotide-gated channels. Nature 386:612-615.

Weitz D, Zoche M, Müller F, Beyermann M, Körschen HG, Kaupp UB, Koch KW (1998) Calmodulin controls the rod photoreceptor CNG channel through an unconventional binding site in the N-terminus of the $\beta$-subunit. EMBO J 17:2273-2284.

Weyand I, Godde M, Frings S, Weiner J, Müller F, Altenhofen W, Hatt H, Kaupp UB (1994) Cloning and functional expression of a cyclicnucleotide-gated channel from mammalian sperm. Nature 368:859-863.

Wheater PR, Burkitt HG, Daniels VG (1987) Functional histology, a text and colour atlas. New York: Churchill Livingstone.

Wiesner B, Weiner J, Middendorff R, Hagen V, Kaupp UB, Weyand I (1998) Cyclic nucleotide-gated channels on the flagellum control $\mathrm{Ca}^{2+}$ entry into sperm. J Cell Biol 142:473-484.

Yu WP, Grunwald ME, Yau KW (1996) Molecular cloning, functional expression and chromosomal localization of a human homolog of the cyclic nucleotide-gated ion channel of retinal cone photoreceptors. FEBS Lett 393:211-215.

Zong X, Zucker H, Hofmann F, Biel M (1998) Three amino acids in the $\mathrm{C}$-linker are major determinants of gating in cyclic nucleotide-gated channels. EMBO J 17:353-362. 